\title{
N-System Amino Acid Transport at the Blood-CSF Barrier
}

\author{
Richard F. Keep and Jianming Xiang \\ Department of Surgery, University of Michigan, Ann Arbor, Michigan, U.S.A.
}

\begin{abstract}
Despite L-glutamine being the most abundant amino acid in CSF, the mechanisms of its transport at the choroid plexus have not been fully elucidated. This study examines the role of $\mathrm{L}_{-}, \mathrm{A}-$-, ASC-, and $\mathrm{N}$-system amino acid transporters in $\mathrm{L}-\left[{ }^{14} \mathrm{C}\right]$ glutamine uptake into isolated rat choroid plexus. In the absence of competing amino acids, approximately half the glutamine uptake was via a $\mathrm{Na}^{+}$-dependent mechanism. The $\mathrm{Na}^{+}$-independent uptake was inhibited by 2-amino-2-norbornane carboxylic acid, indicating that it is probably via an Lsystem transporter. $\mathrm{Na}^{+}$-dependent uptake was inhibited neither by the A-system substrate $\alpha$-(methylamino) isobutyric acid nor by the ASC-system substrate cysteine. It was inhibited by histidine, asparagine, and L-glutamate $\gamma$-hydroxamate, three $\mathrm{N}$-system substrates. Replacement of $\mathrm{Na}^{+}$with $\mathrm{Li}^{+}$had little effect on uptake, another feature of $\mathrm{N}$-system amino acid transport. These data therefore indicate that $\mathrm{N}$-system amino acid transport is present at the choroid plexus. The $V_{\max }$ and $K_{\mathrm{m}}$ for glutamine transport by this system were $8.1 \pm 0.3 \mathrm{nmol} / \mathrm{mg} /$ min and $3.3 \pm 0.4 \mathrm{mM}$, respectively. This system may play an important role in the control of CSF glutamine, particularly when the CSF glutamine level is elevated as in hepatic encephalopathy. Key Words: Choroid plexusGlutamine-Histidine-Rat-Influx.

J. Neurochem. 65, 2571-2576 (1995).
\end{abstract}

L-Glutamine is by far the most abundant amino acid present in CSF (see, e.g., Clarke et al., 1989), and increased cerebral glutamine concentrations appear to be important in the genesis of hepatic encephalopathy (Hawkins and Jessy, 1991; Takahashi et al., 1991; Hawkins et al., 1993). Despite its importance, our knowledge of glutamine transport at the blood-CSF and blood-brain barriers is incomplete. Glutamine is transported by the $\mathrm{Na}^{+}$-independent, leucine-preferring (L-system) amino acid transporter from blood to CSF at the choroid plexus (Segal et al., 1990) and from blood to brain at the cerebral capillaries (Oldendorf and Szabo, 1976; Smith et al., 1987), tissues that are, respectively, sites of the blood-CSF and bloodbrain barriers. However, whether glutamine transport at these tissues is also mediated by the $\mathrm{Na}^{+}$-dependent A- and ASC-systems of Christensen (1975) is uncertain because these transporters participate in glutamine transport in some but not all cells (Thomas and Christensen, 1971; Kilberg et al., 1980; Handlogten et al., 1982; Hundal et al., 1987). In hepatocytes and skeletal muscle glutamine uptake is mediated by another $\mathrm{Na}^{+}{ }_{-}$ dependent transporter, the $\mathrm{N}$-system (Kilberg et al., 1980; Hundal et al., 1987), so named because of the presence of a nitrogen in the side chain of its three naturally occurring substrates, glutamine, histidine, and asparagine (Kilberg et al., 1980). Whether $\mathrm{N}$ system transport is present at the blood-brain barriers has not been determined.

In this study we have examined the role of the L-, $\mathrm{A}-$, ASC-, and N-systems in glutamine uptake into isolated rat choroid plexus. For the $\mathrm{N}$-system transport there are as yet no specific substrates, so we examined whether choroid plexus $\mathrm{Na}^{+}$-dependent glutamine transport shares several properties found for the $\mathrm{N}$ system in hepatocytes and skeletal muscle (Kilberg et al., 1980; Hundal et al., 1987).

\section{MATERIALS AND METHODS}

Experiments were performed on choroid plexuses isolated from pentobarbital ( $50 \mathrm{mg} / \mathrm{kg}$ )-anesthetized male SpragueDawley rats $30-50$ days old. The methods used are based on those of Johanson and co-workers (Smith and Johanson, 1985; Parmelee and Johanson, 1989), which we have previously used to examine potassium transport (Keep et al., 1994; Keep and Xiang, 1995). The lateral ventricle plexuses were weighed and transferred to control buffer at $37^{\circ} \mathrm{C}$. There was a 5-min recovery period before the beginning of any experiment.

\section{Buffers}

Most experiments were performed in bicarbonate buffers that were continuously bubbled with $5 \% \mathrm{CO}_{2} / 95 \% \mathrm{O}_{2}$ and contained $127 \mathrm{~m} M \mathrm{NaCl}, 20 \mathrm{~m} M \mathrm{NaHCO}_{3}, 2.4 \mathrm{~m} M \mathrm{KCl}$, $0.5 \mathrm{~m} M \mathrm{KH}_{2} \mathrm{PO}_{4}, 1.1 \mathrm{~m} M \mathrm{CaCl}_{2}, 0.85 \mathrm{mM} \mathrm{MgCl}_{2}, 0.5 \mathrm{~m} M$ $\mathrm{Na}_{2} \mathrm{SO}_{4}$, and $5 \mathrm{mM}$ glucose ( $\mathrm{pH} 7.4$ ). In experiments where a low- $\mathrm{Na}^{+}$buffer was used to investigate the role of $\mathrm{Na}^{+}$in

Received March 13, 1995; revised manuscript received June 5 , 1995; accepted June 8, 1995.

Address correspondence and reprint requests to Dr. R. F. Keep at Department of Surgery (Neurosurgery), University of Michigan, R5605 Kresge I, Ann Arbor, MI 48109-0532, U.S.A.

Abbreviations used: $\mathrm{BCH}, 2$-amino-2-norbornane carboxylic acid; MeAIB, $\alpha$-(methylamino) isobutyric acid. 
L. $-\left[{ }^{14} \mathrm{C}\right]$ glutamine uptake, buffer $\mathrm{NaCl}$ and $\mathrm{NaHCO}_{3}$ were replaced by choline chloride and choline bicarbonate, respectively, producing a $1 \mathrm{mM} \mathrm{Na}{ }^{+}$solution owing to the presence of $\mathrm{Na}_{2} \mathrm{SO}_{4}$. L-Glutamine, from the addition of isotope $(700$ $\mathrm{n} M$ ), and selected competing amino acids (at $10 \mathrm{mM}$ ) were the only amino acids present in the buffer in most experiments. In one experiment, however, a physiological CSF was used with amino acids at the following concentrations: L-glutamine, $500 \mu M$; L-glutamate, $8 \mu M$; taurine, $6 \mu M$; glycine, $7 \mu M$; L-alanine, $26 \mu M$; L-serine, $25 \mu M$; L-threonine, $25 \mu M$; L-lysine, $21 \mu M$; L-arginine, $18 \mu M$; L-histidine, $13 \mu M$; L-valine, $16 \mu M$; L-leucine, $11 \mu M$; L-isoleucine, $4 \mu M$; L-phenylalanine, $8 \mu M$; L-tyrosine, $8 \mu M$; Lmethionine, $3 \mu M ; L$-asparagine, $8 \mu M$; and l-aspartate, 0.2 $\mu M$ [derived from the procedures of Berg et al. (1993) and Clarke et al. (1989)].

The effect of $\mathrm{Na}^{+}$replacement on $\left[{ }^{14} \mathrm{C}\right]$ glutamine uptake was also examined in a Tris-based artificial CSF containing $140 \mathrm{~m} M \mathrm{NaCl}, 3 \mathrm{~m} M \mathrm{KCl}, 3 \mathrm{~m} M \mathrm{CaCl}_{2}, 1.2 \mathrm{~m} M \mathrm{MgCl}_{2}$, $5 \mathrm{~m} M$ glucose, and $15 \mathrm{~m} M$ Tris ( $\mathrm{pH} \mathrm{7.4)} \mathrm{that} \mathrm{was} \mathrm{bubbled}$ with $100 \% \mathrm{O}_{2}$. This facilitated replacement of $\mathrm{Na}^{+}$with $\mathrm{Li}$ as well as choline.

\section{L-Glutamine uptake}

After the recovery period, the plexuses were transferred to $0.95 \mathrm{ml}$ of bicarbonate buffer with or without drug for $0.5 \mathrm{~min}$. Uptake was started by addition of $0.05 \mathrm{ml}$ of buffer with $\sim 0.2 \mu \mathrm{Ci}$ of $\mathrm{I}_{-}\left[{ }^{14} \mathrm{C}\right]$ glutamine and $0.1 \mu \mathrm{Ci}$ of $\left[{ }^{3} \mathrm{H}\right]-$ mannitol (an extracellular marker). Uptake was terminated after $30 \mathrm{~s}$ by transferring the plexus to iced control buffer and filtering under reduced pressure. The filters $(118 \mu \mathrm{m}$ mesh) were washed three times with the same buffer. The filters and choroid plexuses were then soaked in $0.33 \mathrm{ml}$ of I $M$ hyamine hydroxide (a tissue solubilizer) for $30 \mathrm{~min}$ before addition of scintillation cocktail (Cytoscint) and counting with a dual-channel liquid scintillation counter (Model LS 3801; Beckman, Fullerton, CA, U.S.A.).

Preliminary experiments, where uptake time was varied from 0.25 to $10 \mathrm{~min}$, showed that $\mathrm{L}-\left[{ }^{14} \mathrm{C}\right]$ glutamine uptake was only unidirectional for the first $30 \mathrm{~s}$, and therefore experiments were limited to this time. The uptake of $\mathrm{L}-\left[{ }^{14} \mathrm{C}\right]-$ glutamine into choroid plexus $\left(C_{\mathrm{cp}}\right)$, in microliters per milligram wet weight, was calculated as

$$
C_{\mathrm{cp}}=\frac{C_{\mathrm{l}}-C_{\mathrm{f}}-\left[\left(H_{\mathrm{t}}-H_{\mathrm{f}}\right) \cdot \text { ratio }\right]}{C_{\text {rinedia }}}
$$

where $C_{1}$ is the total $\mathrm{L}-\left[{ }^{14} \mathrm{C}\right.$ /glutamine concentration in the plexus plus filter, $C_{t}$ is a correction for the $\mathrm{L}-\left[{ }^{14} \mathrm{C}\right]$ glutamine binding to the filter, and $C_{\text {media }}$ is the concentration of $\mathrm{L}$ $\left[{ }^{14} \mathrm{C}\right.$ lglutamine in the external media. The term $\left(H_{1}-\right.$ $\left.H_{f}\right) \cdot$ ratio is a correction for extracellular isotope, where $H$ is the concentration of $\left[{ }^{3} \mathrm{H}\right]$ mannitol in the plexus plus filter and $H_{\mathrm{H}}$ is the filter binding of mannitol. Multiplying the difference between these two parameters by the ratio of $\mathrm{L}^{-}$ $\left[{ }^{14} \mathrm{C}\right.$ lglutamine to $\left[{ }^{3} \mathrm{H}\right]$ mannitol in the external medium gives an estimate of the extracellular $\mathrm{L}-\left[{ }^{14} \mathrm{C}\right]$ glutamine content. The unidirectional influx rate for glutamine $(v)$ was calculated by multiplying $C_{\mathrm{cp}}$ by the external unlabeled glutamine concentration and dividing by the duration of the experiment.

To determine the kinetic constants for $\mathrm{Na}^{+}$-independent and -dependent uptake, a nonlinear curve-fitting program was used (Systat 5.2; Systat, Inc., Evanston, IL, U.S.A.). For $\mathrm{Na}^{+}$-independent uptake a two-component model was used:

$$
v=\frac{V_{\max } \cdot[S]}{K_{\mathrm{m}}+[S]}+K_{\mathrm{1}} \cdot[S]
$$

where $[S]$ is the glutamine concentration, $V_{\text {max }}$ and $K_{\mathrm{m}}$ are the maximal velocity and affinity constant for saturable uptake, respectively, and $K_{\mathrm{D}}$ is a diffusion constant for nonsaturable transport. For the $\mathrm{Na}^{+}$-dependent uptake, a simple Michaelis-Menten model was used, with

$$
v=\frac{V_{\text {mix }} \cdot[S]}{K_{\mathrm{m}}+[S]}
$$

\section{Materials}

Amino acids were purchased from Sigma (St. Louis, MO, U.S.A.). L- $\left[{ }^{14} \mathrm{C}\right]$ Glutamine $(260 \mathrm{mCi} / \mathrm{mmol})$ was supplied by Amersham Life Science (Arlington Heights, IL, U.S.A.). $\left[{ }^{3} \mathrm{H}\right]$ Mannitol $(15 \mathrm{Ci} / \mathrm{mmol})$ was obtained from American Radiolabeled Chemicals (St. Louis). Hyamine hydroxide and Cytoscint were purchased from ICN (Costa Mesa, CA, U.S.A.).

\section{Statistics}

Comparisons were made using ANOVA and post hoc multiple comparisons tests ( see text). Differences were considered significant at the $p<0.05$ level (two tailed, unless otherwise stated). Data in the text are mean $\pm S E$ values.

\section{RESULTS}

Reducing the extracellular $\mathrm{Na}^{+}$concentration from 148 to $1 \mathrm{~m} M$ in bicarbonate buffer resulted in a $53 \%$ decline $(p<0.001)$ in choroid plexus $\mathrm{L}^{-}\left[{ }^{14} \mathrm{C}\right]-$ glutamine uptake $(5.08 \pm 0.33$ and $2.38 \pm 0.13 \mu \mathrm{l} /$ $\mathrm{mg} / \mathrm{min}$, respectively; media glutamine concentration, $700 \mathrm{n} M$ ), demonstrating both $\mathrm{Na}^{+}$-dependent and -independent uptake. The mechanisms of $\mathrm{Na}^{+}$-dependent and -independent $\mathrm{L}-\left[{ }^{14} \mathrm{C}\right]$ glutamine uptake were examined by addition of several potentially competing amino acids (at $10 \mathrm{~m} M$ ) in either 148 (Fig. 1A) or 1 (Fig. 1B) $\mathrm{mM} \mathrm{Na}{ }^{+}$. The effect on $\mathrm{Na}^{+}$-dependent uptake was determined by difference (Fig. IC).

Unlabeled L-glutamine inhibited total, $\mathrm{Na}^{+}$-independent, and $\mathrm{Na}^{+}$-dependent uptake. 2-Amino-2-norbornane carboxylic acid $(\mathrm{BCH})$ inhibited total and $\mathrm{Na}^{+}$-independent uptake but had no effect on $\mathrm{Na}^{+}$dependent uptake. $\mathrm{BCH}$ is an L-system substrate (Christensen et al., 1969), and these results indicate that the $\mathrm{Na}^{+}$-independent $\mathrm{L}-{ }^{14} \mathrm{C}$ Iglutamine uptake is via this transporter. $\alpha$-(Methylamino) isobutyric acid (MeAIB), an A-system substrate (Christensen et al., 1965 ), had no effect on total, $\mathrm{Na}^{+}$-dependent, or $\mathrm{Na}^{+}{ }_{-}$ independent uptake, indicating that the A-system is not involved in $\left[{ }^{14} \mathrm{C}\right]$ glutamine transport in this tissue. $\mathrm{L}$ Cysteine reduced total and $\mathrm{Na}^{+}$-independent uptake but had no effect on $\mathrm{Na}^{+}$-dependent uptake. Cysteine is both a substrate for the $\mathrm{Na}^{+}$-independent $\mathrm{L}$ - and the 

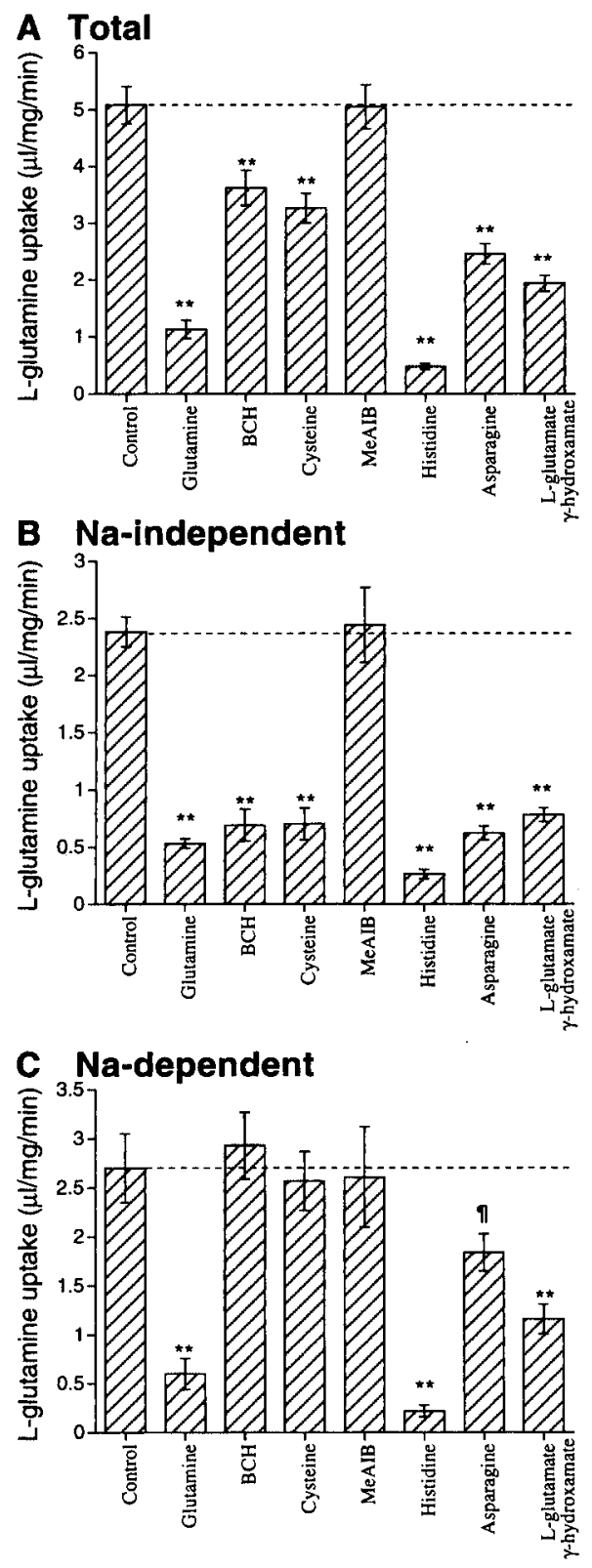

FIG. 1. $L-\left[{ }^{14} \mathrm{C}\right]$ Glutamine uptake in the presence of $(A) 148$ or (B) $1 \mathrm{mM} \mathrm{Na}{ }^{+}$in bicarbonate buffer. Measurements were made in the presence of different potentially competing amino acids $(10 \mathrm{mM})$. Data are mean + SE (bars) values $(n=5-22)$. C: The $\mathrm{Na}^{+}$-dependent $\left[{ }^{14} \mathrm{C}\right]$ glutamine uptake was determined by difference. Significant differences from the control (no competing amino acid) are indicated: ${ }^{*} p<0.01$ level. $p<0.05$, significant difference by one-tailed test. Comparisons with the control were made using Dunnett's (A and $\mathrm{B}$ ) and Bonferroni (C) multiple comparison tests.

$\mathrm{Na}^{+}$-dependent ASC-systems (Kilberg et al., 1979; Tayarani et al., 1987). The results on choroid plexus indicate that cysteine reduces $\left[{ }^{14} \mathrm{C}\right]$ glutamine uptake via the former and that $\mathrm{Na}^{+}$-dependent uptake is not via the ASC-system. L-Histidine reduced total, $\mathrm{Na}^{+}$- independent, and $\mathrm{Na}^{+}$-dependent uptake. Histidine is an L-, A-, and N-system substrate (Christensen, 1975; Kilberg et al., 1980). As the A-system does not appear to participate in glutamine uptake, these results suggest that histidine acts to inhibit $\left[{ }^{14} \mathrm{C}\right]$ glutamine uptake by competing for both the $\mathrm{Na}^{+}$-independent $\mathrm{L}$ - and the $\mathrm{Na}^{+}$-dependent $\mathrm{N}$-system.

As yet there are no specific substrates for the $\mathrm{N}$ system transporter. However, work on other tissues has demonstrated certain properties of this system that we have also examined in choroid plexus. L-Asparagine is the third naturally occurring amino acid that is transported by the $\mathrm{N}$-system in liver and skeletal muscle, although its affinity for the transporter appears to be less than that of either L-glutamine or L-histidine (Kilberg et al., 1980). Choroid plexus $\mathrm{Na}^{+}$-dependent glutamine uptake was inhibited by L-asparagine $(p<0.05$ by one-tailed $t$ test), although to a lesser degree than by glutamine and histidine (Fig. 1). L-Glutamate $\gamma$ hydroxamate reduces $\mathrm{N}$-system glutamine uptake in both hepatocytes and skeletal muscle (Kilberg et al., 1980; Low et al., 1991), and it has the same action on $\mathrm{Na}^{+}$-dependent glutamine uptake in choroid plexus ( $p<0.01$; Fig. 1C). Finally, $\mathrm{N}$-system uptake is less affected by $\mathrm{Na}^{+}$replacement with $\mathrm{Li}^{+}$than either the A- or ASC-system transporter (Kilberg et al., 1980). In choroid plexus $\mathrm{Li}^{+}$substitution in Tris buffer did not produce a significant reduction in choroid plexus $\left[{ }^{14} \mathrm{C}\right]$ glutamine uptake, in contrast to the effect of choline substitution (Fig. 2).

The kinetics of L-glutamine uptake were examined in bicarbonate buffer by varying $\mathrm{L}$-glutamine concentrations from $1 \mu M$ to $10 \mathrm{~m} M$ in the presence of 148 or $1 \mathrm{mM} \mathrm{Na}{ }^{+}$(Fig. 3). $\mathrm{Na}^{+}$-dependent uptake had a $K_{\mathrm{m}}$ of $3.3 \pm 0.4 \mathrm{mM}$ and $V_{\max }$ of $8.1 \pm 0.3 \mathrm{nmol} / \mathrm{mg} /$ min. $\mathrm{Na}^{+}$-independent uptake was divided into two components: a saturable uptake system, with a $K_{\mathrm{m}}$ of $1.1 \pm 0.6 \mathrm{mM}$ and a $V_{\max }$ of $2.4 \pm 0.7 \mathrm{nmol} / \mathrm{mg} / \mathrm{min}$, and an apparently nonsaturable mechanism, with a $K_{\mathrm{D}}$ of $0.32 \pm 0.06 \mu \mathrm{l} / \mathrm{mg} / \mathrm{min}$. These measurements were made in the absence of possible competing amino acids that might normally be present in CSF. However, uptake in the presence of physiological CSF concentrations of amino acids in 148 and $1 \mathrm{mM} \mathrm{Na}{ }^{+}$was not significantly different from uptake in the presence of glutamine alone (Fig. 4), which suggests that the con-

FIG. 2. $\mathrm{L}-\left[{ }^{14} \mathrm{C}\right]$ Glutamine up take in Tris buffer in the presence of a normal $\mathrm{Na}^{+}$concentration or when $\mathrm{Na}^{+}$was replaced with choline or $\mathrm{Li}^{\prime}$. Data are mean $\pm \mathrm{SE}$ (bars) values $(\mathrm{n}$ $=5) .{ }^{* *} p<0.01$ versus $\mathrm{Na}^{+}$ $\dagger p<0.05$ versus choline. Comparisons between values are by ANOVA with Newman-Keuls multiple comparisons test.

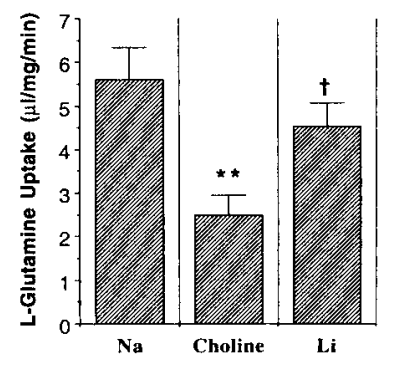




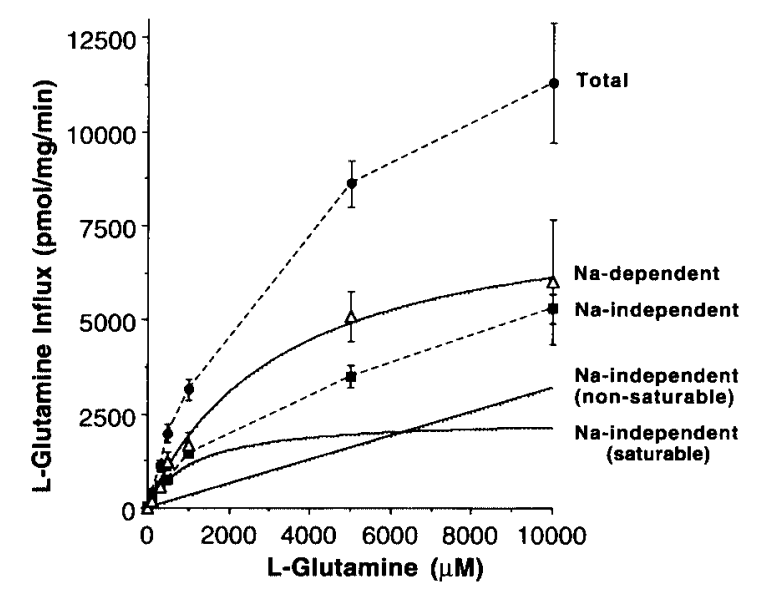

FIG. 3. Effect of external L-glutamine concentration on glutamine influx into choroid plexus in bicarbonate buffer. Measurements were made in the presence of 148 or $1 \mathrm{mM} \mathrm{Na}^{+}$(total and $\mathrm{Na}$-independent uptake, respectively). Data are mean \pm SE (bars) values $(n=5-22)$. The $\mathrm{Na}^{+}$-dependent flux was determined by difference and fit to Michaelis-Menten kinetics. The $\mathrm{Na}^{+}$-independent uptake was fit to a two-component model, with one system being saturable and the other nonsaturable.

centration of other amino acids in the CSF is normally not great enough to compete with glutamine for transport. It is possible, however, that some amino acids may be stimulating L-system transport, offsetting the effects of competition.

\section{DISCUSSION}

The results presented here indicate that $\mathrm{L}$-glutamine uptake into the isolated rat choroid plexus is via both the $\mathrm{Na}^{+}$-independent $\mathrm{L}$-system and the $\mathrm{Na}^{+}$-dependent $\mathrm{N}$-system. L-system-mediated transport has previously been identified in mammalian choroid plexus (see, e.g., Davson et al., 1982; Segal et al., 1990). As with the blood-brain barrier (Betz and Goldstein, 1978), L-system transport appears present on both the blood- and brain-facing membranes of the choroid plexus and facilitates diffusion in either the blood-toCSF (Segal et al., 1990) or CSF-to-blood (Davson et al., 1982) direction.

In contrast, $\mathrm{N}$-system transport has not been previously identified at the choroid plexus. In terms of substrate specificity, $\mathrm{Na}^{+}$dependence, and $\mathrm{Li}^{+}$tolerance, the choroid plexus $\mathrm{N}$-system transporter appears similar to that in hepatocytes and skeletal muscle (Kilberg et al., 1980; Hundal et al., 1987; Low et al., 1991 ). Also like in these tissues, L-glutamine transport at the choroid plexus is not mediated by either the Aor the ASC-system (Kilberg et al., 1980; Hundal et al., 1987). The capacity of the choroid plexus for glutamine transport is indicated by the similarity in the $V_{\text {max }}$ for $\mathrm{N}$-system transport $(8 \mathrm{nmol} / \mathrm{mg}$ wet weight/ min) to that found in hepatocytes $18 \mathrm{nmol} / \mathrm{mg}$ of intracellular water/min (Kilberg et al., 1980)].

In the sheep, glutamine uptake from blood to CSF is not $\mathrm{Na}^{+}$dependent (Segal et al., 1990). If this is also the case in the rat, it appears that the N-system transporter has an asymmetrical distribution, i.e., it is only present on the apical (brain-facing) membrane. It may therefore serve to move glutamine and the other naturally occurring substrates, histidine and asparagine, from the CSF to blood. Despite the presence of such a mechanism for glutamine transport at the blood--CSF barrier, the concentration of glutamine in CSF is only slightly less than that of plasma (see, e.g., Clarke et al., 1989). This suggests that glutamine clearance is being replaced by brain glutamine synthesis or that apical glutamine uptake is not matched under normal conditions by glutamine efflux across the basolateral (blood-facing) membrane into blood. In contrast, the level of histidine, an essential amino acid, is substantially less in CSF compared with plasma (see, e.g., Clarke et al., 1989).

The N-system transporter may be of particular importance in the clearance of CSF glutamine during hepatic encephalopathy, when hyperammonemia leads to cerebral glutamine synthesis and increased brain and CSF glutamine concentrations (for review, see Cooper and Plum, 1987). In this disease CSF glutamine content has been reported to increase from $\sim 0.5$ to 2.5 $\mathrm{m} M$ (Watanabe et al., 1984), which would be expected to increase clearance from the CSF through the $\mathrm{N}$ system transporter because its $K_{\mathrm{m}}$ is $\sim 3 \mathrm{mM}$. Indeed, Gjedde et al. (1978) have reported an increase in glutamine loss from the brain during hepatic encephalopathy induced by portacaval shunting, and Dejong et al. (1992) reported an increase during hyperammonemia induced by liver insufficiency. The increase in brain

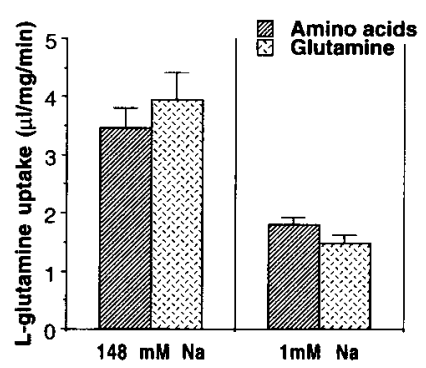

FIG. 4. $\mathrm{L}-\left[{ }^{14} \mathrm{C}\right]$ Glutamine uptake into isolated choroid plexus in the presence of either physiological concentrations of amino acids (including $500 \mu \mathrm{M}$ glutamine; see Materials and Methods) or $500 \mu M$ glutamine alone. Measurements were made in the presence of 148 or $1 \mathrm{mM} \mathrm{Na}$ ' (bicarbonate buffer). Data are mean $\pm S E$ (bars) values $(n=7-10)$. $\mathrm{Na}$ ' removal produced a significant decrease in uptake with $(p<0.01)$ and without the presence $(p<0.001)$ of the other amino acids. The presence of the other amino acids made no significant difference in uptake in the presence of either 148 or $1 \mathrm{mM} \mathrm{Na}^{+}$. Comparisons between values were by ANOVA with a Newman-Keuls multiple comparisons test. 
glutamine concentration during hepatic encephalopathy appears to be necessary to the progression of this disease (Hawkins and Jessy, 1991; Takahashi et al., 1991; Hawkins et al., 1993) stressing the potential importance of this clearance mechanism. With a $V_{\max }$ of $8 \mathrm{nmol} / \mathrm{mg}$ wet weight $/ \mathrm{min}$, the $\mathrm{N}$-system transporter in $6 \mathrm{mg}$ of choroid plexus would be capable of clearing the whole glutamine content of a normal rat brain $(\sim 8,000 \mathrm{nmol})$ in $\sim 3 \mathrm{~h}$ if the uptake were matched by glutamine efflux across the basolateral membrane into blood.

The mechanisms by which increases in brain glutamine levels may lead to hepatic encephalopathy are still uncertain. Brain glutamine, by acting as an osmolyte, may contribute directly to brain edema (Takahashi et al., 1991). However, the uptake of amino acid substrates of the L-system is also increased in hepatic encephalopathy (Zanchin et al., 1979; Mans et al., 1983). In isolated cerebral microvessels, intracellular glutamine can stimulate amino acid influx via the Lsystem (James and Fischer, 1981; Cangiano et al., 1983), suggesting that the increased transport in hepatic encephalopathy might result from the elevated brain glutamine concentrations. As several of the amino acids transported by the L-system carrier are neurotransmitter precursors, increased transport may lead to a derangement in brain function. If the $\mathrm{N}$-system transporter is present at the blood-brain as well as the blood-CSF barrier, it may be a major determinant of intracellular glutamine level and hence the degree of L-system transport stimulation.

In summary, a major component of glutamine transport in the isolated choroid plexus is via the $\mathrm{Na}^{+}$dependent $\mathrm{N}$-system. This may have important consequences for the regulation of the brain concentration of this amino acid under normal and pathophysiological conditions. Glutamine transport via this system will also affect the transport of other amino acids that are transported by either the $\mathrm{N}$ - or the L-system transporter.

Acknowledgment: This work was supported by the Department of Surgery (Neurosurgery), University of Michigan. We thank Dr. A. Lorris Betz for many helpful comments and suggestions.

\section{REFERENCES}

Berg S. L., Balis F. M., McCully C. L., Godwin K. S., and Poplack D. G. (1993) Pharmacokinetics of PEG-L-asparaginase and plasma and cerebrospinal fluid L-asparagine concentrations in the rhesus monkey. Cancer Chemother. Pharmacol. 32, 310-314.

Betz A. L. and Goldstein G. W. (1978) Polarity of the bloodbrain barrier: neutral amino acid transport into isolated brain capillaries. Science 202, 225-227.

Cangiano C., Cardelli P. C., James J. H., Rossi-Fanelli F., Patrizi M. A., Brackett K. A., Strom R., and Fischer J. E. (1983) Brain microvessels take up large neutral amino acids in exchange for glutamine. J. Biol. Chem. 258, 8949-8954.

Christensen H. N. (1975) Recognition sites for material transport and information transfer. Curr. Top. Membr. Transp. 6, 227258.

Christensen H. N., Oxender D. L., Liang M., and Vatz K. A. ( 1965 ) The use of $N$-methylation to direct the route of mediated transport of amino acids. J. Biol. Chem. 240, 3609-3616.

Christensen H. N., Handlogten M. E., Lam I., Tager H. S., and Zand R. (1969) A bicyclic amino acid to improve discriminations among transport systems. J. Biol. Chem. 244, 1510-1520.

Clarke D. D., Lajtha A. L., and Maker H. (1989) Intermediary metabolism, in Basic Neurochemistry: Molecular, Cellular, and Medical Aspects, 4th edit. (Siegel G. J., Agranoff B. W., Albers R. W., and Molinoff P. B., eds), pp. 541-564. Raven Press, New York.

Cooper A. J. L. and Plum F. (1987) Biochemistry and physiology of brain ammonia. Physiol. Rev. 67, 440-519.

Davson H., Hollingsworth J. G., Carey M. B., and Fenstermacher J. D. (1982) Ventriculocisternal perfusion of twelve amino acids in the rabbit. J. Neurobiol. 13, 293-318.

Dejong C. H. C., Kampman M. T., Deutz N. E. P., and Soeters P. B. (1992) Cerebral cortex ammonia and glutamine metabolism during liver insufficiency-induced hyperammonemia in the rat. J. Neurochem. 59, 1071-1079.

Gjedde A., Lockwood A. H., Duffy T. E., and Plum F. (1978) Cerebral blood flow and metabolism in chronically hyperammonemic rats: effect of an acute ammonia challenge. Ann. Neurol. 3, 325-330.

Handlogten M. E., Kilberg M. S., and Christensen H. N. (1982) lncomplete correspondence between repressive and substrate action by amino acids on transport systems $\mathrm{A}$ and $\mathrm{N}$ in monolayered rat hepatocytes. J. Biol. Chem. 257, 345-348.

Hawkins R. A. and Jessy J. (1991) Hyperammonemia does not impair brain function in the absence of glutamine synthesis. Biochem. J. 277, 697-703.

Hawkins R. A., Jessy J., Mans A. M., and De Joseph M. R. (1993) Effect of reducing brain glutamine synthesis on metabolic symptoms of hepatic encephalopathy. J. Neurochem. 60, $1000-$ 1006.

Hundal H. S., Rennie M. J., and Watt P. W. (1987) Characteristics of L-glutamine transport in perfused rat skeletal muscle. J. Physiol. (Lond.) 393, 283-305.

James J. H. and Fischer J. E. (1981) Transport of neutral amino acids at the blood-brain barrier. Pharmacology 22, 1-7.

Keep R. F. and Xiang J. (1995) Choroid plexus potassium cotransport: modulation by osmotic stress and external potassium. $J$. Neurochem. 64, 2747-2754.

Keep R. F., Xiang J., and Betz. A. L. ( 1994 ) Potassium cotransport at the rat choroid plexus. Am. J. Physiol. 267, C1616-C1622.

Kilberg M. S., Christensen H. N., and Handlogten M. E. (1979) Cysteine as a system-specific substrate for transport system ASC in rat hepatocytes. Biochem. Biophys. Res. Commun. 88, $744-751$.

Kilberg M. S., Handlogten M. E., and Christensen H. N. (1980) Characteristics of an amino acid transport system in rat liver for glutamine, asparagine, histidine and closely related analogs. J. Biol. Chem. 255, 4011-4019.

Low S. Y., Taylor P. M., Ahmed A., Pogson C. I., and Rennie M. J. (1991) Substrate-specificity of glutamine transporters in membrane vesicles from rat liver and skeletal muscle investigated using amino acid analogues. Biochem. J. 278, 105-111.

Mans A. M., Biebuyck J. F., and Hawkins R. A. (1983) Ammonia selectively stimulates neutral amino acid transport across the blood-brain barrier. Am. J. Physiol. 245, C74-C77.

Oldendorf W. H. and Szabo J. (1976) Amino acid assignment to one of three blood-brain barrier amino acid carriers. Am. J. Physiol. 230, 94-98.

Parmelee J. T. and Johanson C. E. (1989) Development of potassium transport capability by choroid plexus of infant rats. Am. $J$. Physiol. 256, R786-R791.

Segal M. B., Preston J. E., Collis C. S., and Zlokovic B. V. (1990) Kinetics and $\mathrm{Na}$ independence of amino acid uptake by blood 
side of perfused sheep choroid plexus. Am. J. Physiol. 258, F1288-F1294.

Smith Q. R. and Johanson C. E. (1985) Active transport of chloride by lateral ventricle choroid plexus of the rat. Am. J. Physiol. 249, F470-F477.

Smith Q. R., Momma S., Aoyagi M., and Rapoport S. I. (1987) Kinetics of neutral amino acid transport across the blood-brain barrier. J. Neurochem. 49, $1651-1658$.

Takahashi H., Koehler R. C., Brsilow S. W., and Traystman R. J. (1991) Inhibition of brain glutamine accumulation prevents cerebral edema in hyperammonemic rats. Am. J. Physiol. 261, H825-H829.

Tayarani I., Lefauconnier J.-M., Roux F., and Bourre J.-M. (1987)
Evidence for an alanine, serine, and cysteine system transport in isolated brain capillaries. J. Cereb. Blood Flow Metab. 7, 585-591.

Thomas E. D. and Christensen H. N. (1971) Nature of the cosubstrate action of $\mathrm{Na}^{+}$and neutral amino acids in a transport system. J. Biol. Chem. 246, 1682-1688.

Watanabe A., Takei N., Higashi T., Shiota T., Nakatsukasa H., Fujiwara M., Sakata T., and Nagasime H. (1984) Glutamic acid and glutamine levels in serum and cerebrospinal fluid in hepatic encephalopathy. Biochem. Med. 32, 225-231.

Zanchin G., Rigotti P., Dussini N., Vassanelli P., and Battistin L. (1979) Cerebral amino acid levels and uptake in rats after portocaval anastomosis. II. Regional studies in vivo. J. Neurosci. Res. 4, 301-310 